\title{
Changes in the industrial environment and CALS
}

\author{
L. Zuijdgeest \\ PDI/CALS Centre \\ P.O. Box 770 \\ 3430 AT Nieuwegein, The Netherlands \\ Phone: +31 (0)30 6021551; Fax: +31(0)306022469 \\ E-mail: calsnl@euronet.nl
}

\begin{abstract}
CALS is a management strategy for the implementation of modern working methods supported by information technology based on widely accepted standards. Modern working methods are based on early involvement of all relevant functions. Product data should be available for all concerned. The information technology and the necessary standards will be increasingly model-based rather than document based. CALS has international support from all industry sectors.
\end{abstract}

\section{Keywords}

CALS, information technology, STEP, concurrent engineering, logistic support, SGML

\section{INTRODUCTION}

In the past few decades, industry has seen quite a few changes. Never, it seems, has the pace of change been so high as right now. Major companies, believed to be there forever, came close to extinction. The ultimate punishment for not adapting to change. Nearly always management points to on or more reasons factors beyond control to indicate that the company itself is not to blame.

Despite all best intentions, most companies, large and small, have suffered great hardship in the past decade. Some have survived and have been strengthened by the experience, some are still suffering and others did not survive. Examples are well know, also in the Eindhoven region, the industrial heart of Holland. 
Changes in the industrial environment not only present threats, but also opportunities. When seized, opportunities can lead to differentiation from competitors and increased value for its owners.

Currently industry faces an number of changes. Changes that require a new of thinking on how to conduct business and a new way of thinking on the use of information technology.

\section{CHANGES IN THE INDUSTRIAL ENVIRONMENT}

\section{System or product complexity}

In the past centuries, scientific and technological developments have been successful by man's ability to reduce systems to easy understandable and manageable components. This approach has resulted in many highly specialised functions, often organised in a Taylor-like fashion leading to 'functional islands'.

In the past decade or two, the disadvantages of this approach have become more and more obvious.

With increasing complexity of products and systems, it is clear that their behaviour cannot be understood and managed by its components alone. The relationships between components are often more important for the behaviour of systems than the components.

In designing new systems or products, more attention should be paid to the relations between components. This means that the functional islands have to work closely together, if not integrate.

\section{Focus on client's business}

Selling products in today's market requires an in depth feel for the clients business. In a recent study conducted in Dutch industry, the overall conclusion was that time-to-market is the factor that counted most in purchasing products. Product cost came next and product quality came last of these three. An additional factor that gains importance is cost-of-ownership or life-cycle cost. Although well-known in the aerospace and defence-business, the factor is less appreciated elsewhere. Mostly because the purchasing party sees initial expense and operation cost independent of each other. Literature shows the following issues in different industry sectors (table 1).

Table 1 Business issues in different industry sectors

\begin{tabular}{|l|l|l|l|}
\hline $\begin{array}{l}\text { Consumer } \\
\text { Products }\end{array}$ & $\begin{array}{l}\text { Industrial } \\
\text { Products }\end{array}$ & Industrial Projects & $\begin{array}{l}\text { Infrastructure } \\
\text { projects }\end{array}$ \\
\hline $\begin{array}{l}\text { Reduce time to } \\
\text { market }\end{array}$ & Reduce cost & $\begin{array}{l}\text { Reduce proposal } \\
\text { lead-time }\end{array}$ & Meet quality \\
\hline $\begin{array}{l}\text { Continuous reduce } \\
\text { cost }\end{array}$ & Reduce lead-time & Reduce project cost & Reduce cost \\
\hline $\begin{array}{l}\text { Continuous improve } \\
\text { quality }\end{array}$ & Improve quality & $\begin{array}{l}\text { Realise set of } \\
\text { functional standards }\end{array}$ & $\begin{array}{l}\text { Manage and reduce } \\
\text { lead-time }\end{array}$ \\
\hline e.g. telephone & e.g. car & e.g. ship & e.g. bridge \\
\hline
\end{tabular}


Every business-function has its effect on other functions and a clear overall insight is necessary to reduce development and production time, keep initial and life-cycle cost low and achieve acceptable quality.

\section{Concentrate on core business}

Also in the past decade, companies felt the need to concentrate on core-business and sold-off many of their non-core-business activities. Former departments became companies in their own right or were taken over by other companies and offered their services to the previous owner.

\section{Business-unit structure}

In-house the situation changed even more. Business-unit structures were introduced and the business-units adopted a free market approach and obtained the freedom to hire services from other business-units or from outside the company.

When combined with the increasing product complexity and the need to integrate functions, companies now face the challenge to get both internal business-units and external contractors working closely together on product development and manufacture.

\section{Subcontracting}

The trend to focus on core business and the trend towards independent business units implies the wish to make full use of the capabilities of subcontractors. Until recently, end manufacturers thought it necessary to make detailed specifications for contractors. These contractors only supply to specification, no other input is required from them. The specification depth is rapidly decreasing. The end manufacturer provides functional specifications and boundary conditions when applicable, and the contractor goes to work, using his full expertise. He thus not only saves the end manufacturer the cost of having the expertise in house, but also creates added value for his own business.

\section{Virtual company}

All these trends signify an increase in the importance of the supplier. The structure in the industry starts to look like a network of more or less equivalent partners, rather than the traditional chain of suppliers.

\section{Concurrent engineering}

Time to market, initial cost, cost of ownership and product quality are, often in this order, the key elements on which a company or an individual purchases a product. In many industrial sectors, the phenomenon of concurrent engineering is seen as the way to improve on these key elements. Within companies serious efforts have been made to achieve this concurrent, multidisciplinary approach. But with the increasing importance of suppliers, an internal concurrence will not suffice. Essentially the suppliers are still sequentially involved. Given the potential contributions suppliers can make to effectivity and efficiency, a more involving working method is necessary. The concurrence should also involve the main suppliers: cooperative engineering (figure 1). 


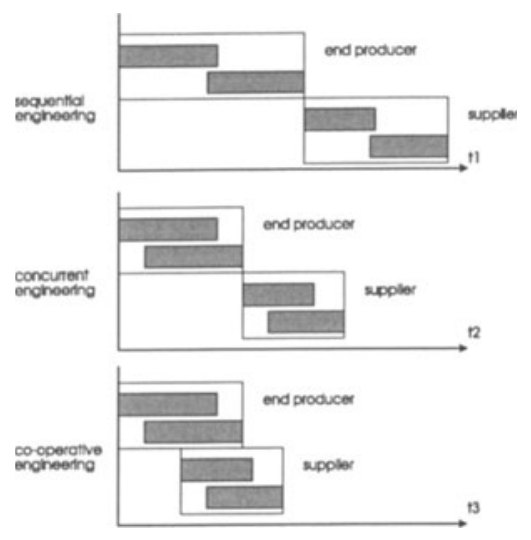

Figure 1 Decreasing product development time with co-operative engineering

\section{Quality of management}

Business functions need to work closely together. Multidisciplinary teams are formed to integrate functions and get access to knowledge in all relevant departments. Many companies that have tried to form multidisciplinary teams had difficulty implementing them. To get a group of people from different backgrounds communicating is quite difficult to achieve in practice.

New organisations and working methods require a new kind of management. The traditional power-base of the middle manager is under threat.

In order to make co-operative engineering work, new views on conducting a business are necessary. An end manufacturer and his suppliers can no longer be seen as a group of individual companies. The group of companies should function as a virtual enterprise. The virtual enterprise can only function when departmental thinking no longer exists. In multidisciplinary teams information should be exchanged freely and responsibility should be shared by the participating disciplines.

\section{ADAPTING TO CHANGE}

When looking at the changes in industry there is not one simple way for companies to adapt. Companies must realise that the new way of conducting their business has to be based on the timely involvement of experts. Already in the conceptual stages of product development a great part of the product's life-cycle properties, will be determined. Properties include manufacturability, manufacturing cost, maintainability and maintenance cost, quality, re-use and so on. So in the stages of conceptual design and engineering, companies should also work on production planning, logistic support and technical and training documentation. 
To achieve this, processes throughout the company will have to be reviewed and revised. For instance, on the one hand engineering is often seen as a cost factor with rather low investments. The manufacturing department on the other hand gets great attention in order to optimise production process. The manufacturing department heavily depends on the quality of the design. Although this has been known for a long time, both industry and government are slow to adapt.

Adapting to change would mean changing business processes, changing the role of people, making use of widely accepted standards (both functional and technical) and use modern information technology based on these standards.

A coherent overall strategy is necessary involving business processes, people, information and (information) technology. CALS is such a strategy (figure 2).

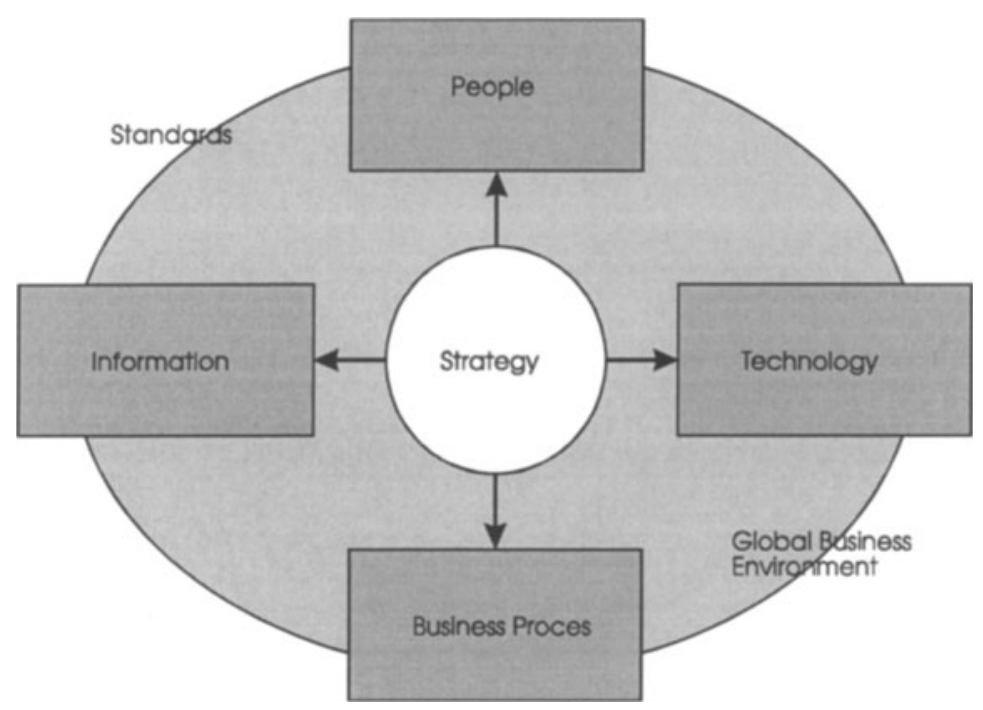

Figure 2 CALS: a coherent overall strategy involving business processes, people, information and (information) technology

\section{INTRODUCING CALS}

\subsection{Where did CALS come from?}

CALS started life on the morning of 24 September 1985 when William H. Taft Issued a memorandum 'Subject: Computer Aided Logistic Support'. This memorandum from the US Deputy Secretary of Defence to the secretaries of all US military departments and directors of defence agencies outlined a strategy for major improvements in supportable weapon system 
designs, and in the accuracy, timeliness and use of logistic technical information. This technical information includes technical manuals, training material en product definition data.

Taft launched another memorandum on 5 August 1998 in which CALS is expanded to cover the acquisition process: Computer-aided Acquisition and Logistic Support. This memorandum demanded the use of national and international standards for delivery, access and management of digital data.

CALS is now defined as Continuous Acquisition and Life-cycle Support, shedding its image of a technically oriented strategy and emphasising the life-cycle concept. The CALS Strategy is now globally accepted as 'the development of an integrated data environment created by applying the best commercial technologies, processes and standards for the development, management, exchange and use of business and technical information among government and industry enterprises'. Or in other words, CALS is a management strategy to improve business processes and make better use of the most important production factor, information.

CALS now has global support, in the United States, in Europe and in the Pacific Rim in both defence and non-defence industry. Supporting industry bodies have been founded in the past few years to discuss progress, CALS-programs and projects, and experiences.

\subsection{Harmonising Business Processes, Standards and Information Technology}

The technological basis of the virtual enterprise lies in information technology. Organisational and procedural aspects are by far the most important of the virtual enterprise. Information technology is the enabling technology. Without it, the virtual enterprise would be impossible to achieve.

The virtual enterprise and information technology based on standards is what the CALS strategy is all about. CALS, Continuous Acquisition and Life-cycle Support, originates from an industry sector where many companies are involved with the development and production of very complex capital goods that have to meet high demands in product quality and maintainability.

For the business processes to function, access to information by all concerned is necessary. This implies an information infrastructure in which data can be generated, stored, managed, retrieved and archived. Parties concerned should have access based on their roles and responsibilities in the business processes.

\subsection{CALS Phases}

The CALS strategy is designed to be implemented in two steps (figure 3). The first step, which has been more or less completed, is focused on the migration from a paper based information flow to a digital information flow. In the current phase the exchange of data between 
applications is based on neutral (industry) standards. Edifact and Iges being examples. This is an interim solution.

The second step is aimed at the migration from the interim solution towards integrated product model databases. In the defence-industry, CALS is based on the CITIS-concept. CITIS is the acronym for Contractor Integrated Technical Information Services and is intended to provide government agencies with real-time, on-line access to technical information that exists and is maintained at the contractor site. In fact, government agencies have outsourced the management of weapon systems to the prime contractor.

CITIS provides access to design data, data for logistic support, training manuals and maintenance manuals. For each of these data types, separate functional and technical standards are prescribed.
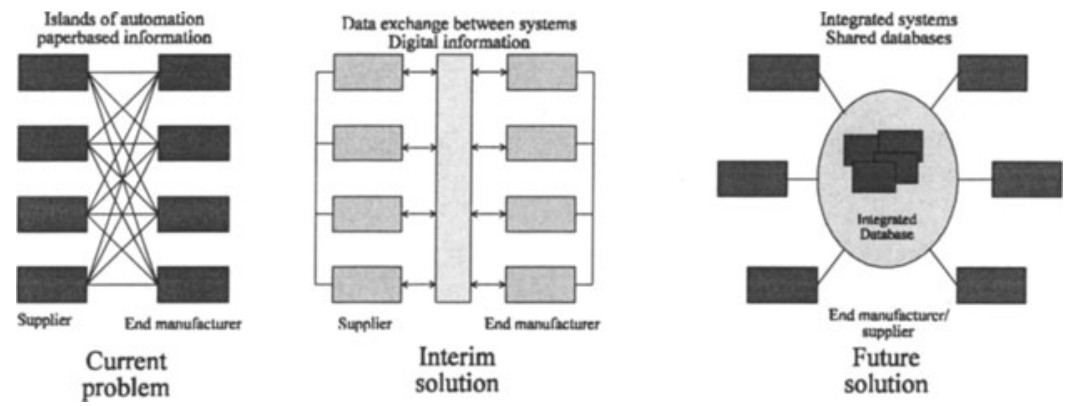

\section{Figure 3 CALS phases}

Ideally, these standards should provide the possibility create data models based on activity models. This way, the information infrastructure meets the requirements of the business process.

The most prominent standards are:

- SGML: ISO 8879 and related standards like HyTime for modelling textual information and linking objects for hypermedia purposes;

- LSA(R): MIL-STD-1388-1A and 2B functional and technical standards for logistic support analysis and modelling logistic support databases;

- STEP: ISO 10303 functional and technical standard for modelling product data.

Due to the severe budget reductions, governments have been looking for ways to cut defence expenses. The cost to maintain specific military standards for the defence industry is so high, that Secretary of Defence Perry issued the Perry-memorandum in which he announced the migration towards internationally accepted standards and more off-the-shelf products. 
For instance, the LSA(R)-standards are currently harmonised for the NH90-project and a first draft will be submitted to ISO for further development and balloting.

\subsection{STEP}

STEP has world-wide support. The real value of STEP is that is both an architecture and a standard. It supplies the methods to develop activity and data models and the implementation of product databases for managing, sharing and archiving product data throughout the product's life-cycle. It implies a separation of functionality of computer applications and data representation. Ultimately, computer applications should read/write directly in STEP databases.

\subsection{STEP drawbacks}

Since its conception in 1984 a lot of effort has been put into the development of STEP. The results however, have not lived up to the expectations. Partly this is due to the ISO standardisation process, and partly due to the structure and complexity of STEP.

The basis of STEP originally was a single data model, called IPIM (Integrated Product Information Model) that encompasses all industry sectors, all disciplines and all types of information. The first version of IPIM was released in 1988 and consisted of hundreds of pages, while only covering a small portion of its scope. It would be impossible to cope with such a modelling task.

A more pragmatic view was adopted with Application Protocols (APs). An AP contains a data model for a particular type of data and a particular industry sector. Although more sensible than the IPIM, APs still have large scopes that require extensive data modelling and a lot of time. The Application Protocol for the automotive industry is a prime example. Its scope is so large that consensus might be difficult to attain.

Furthermore, APs must be used in conjunction with each other and therefore be interoperable. They are not. Simply because the industry specific terminology is used without reference to other APs.

This problem with interoperability led to yet another approach, based on the enterprise rather than on the industry sector. Small standardised STEP-components called Application Interpreted Constructs (AICs), provide building blocks for STEP product models. The drawback is the expected volume of these building blocks.

On the other hand, companies can tailor their information needs more precisely to their processes. In order to do so, software tools must be available to facilitate this tailoring process. This might lead to decreased interoperability but again availability of tools should be sufficient to counter this potential problem. 


\section{CONCLUSIONS AND FUTURE}

Changes in the industrial environment create the need for a coherent strategy on processes, people, standards and information technology. Not one of these factors will do without the others. Standards are becoming increasingly available to support processes, although not without problems.

Companies should focus first and foremost on their business processes. Only then should they start working on their information infrastructure. Information technology should ideally be based on widely accepted standards. When standards are not yet mature, pragmatism should take over and implementation should be based on what is available. Under no circumstances the absence of matured standards can be an excuse for not adapting to change.

\section{REFERENCES}

In the composition of this paper the author used various sources amongst which:

- Engineering Data Newsletter (ed. K. Al-Timimi)

- Presentation 'From supplier chain to supplier network' by W.F. Gielingh at the PDI/CALS Conference 1995

- CALS Handbook by PDI/CALS Centre

- Introductory Course on CALS by PDI/CALS Centre

\section{BIOGRAPHY}

L. (Bertus) Zuijdgeest MSc. founded with others in 1992 the PDI/CALS Centre of which he is currently managing director. $\mathrm{He}$ is involved in many activities to increase the awareness and knowledge in Dutch industry in modern IT and standards, amongst which STEP-projects in the process and automotive industry.

$\mathrm{He}$ also is CAD-editor for CA Techniek, the leading CAD/CAM/CAE-magazine in the Netherlands.

Previously he worked as project manager on projects involving CIM and artificial intelligence. 